\title{
IMPROVEMENTS OF JAPANESE SURGICAL TRAINING FOR THE 21ST CENTURY :
}

\section{Problems and suggestions from surgeons all over the world.}

\author{
Chair persons' comment \\ ${ }^{*}$ Hiroaki Osada, MD and ${ }^{* *}$ Masatoshi Ikeshita, MD. \\ St. Marianna University, School of Medicine, \\ Department of Surgery, Divisions of *Chest Surgery \\ and $^{* *}$ Cardiovascular Surgery
}

A revolutionary change has been recently required in every aspect of the social system of Japan. So is in the postgraduate training system in surgery. But, why and for what? It is true that not a few Japanese authors are offering new information in each recent issue of internationally leading journals, both in laboratory and clinical research fields. Increasing activity in academic field does, however, not necessarily mean improving quality of clinical performance of surgeons in general. Patients are always looking for skillful and reliable surgeons at hand, paying less attention to their academic background. Although there is no question that academism is the essential nourishment for surgeons, nourishment alone is not enough for full growth. Long-standing university-based academism-oriented surgery in Japan is now exposed to criticism in terms of socio-economic concern.

Each surgeon could become independent much earlier with less own financial burden and time cost, to serve longer and more efficiently in the daily practice. For that purpose remodeling of the framework is mandatory in postgradualte training courses, with focus shifting from paper work to clinical ability being lined with academism as the source of reasonability. Another social concern is, in relation to the above, proper number of surgeons on the national ground. It is hard to be against the opinion that there are already too many surgeons here in Japan. We have never tried seriously to calculate this. Certainly this would have a close relationship to the cost of the social, and hopefully private practice if being adjusted properly. Issue of the total medical cost has also to be approached from this stand point of view, apart from a priori discussion to cut or not to cut it. In addition to this our training system seems internationally not to be very attractive for the people in foreign countries. Easy to see the reason as because it is not predictive and not authorized or qualified enough.

It is a great fortune for us to have had an opportunity of having the following leading discussants at the 25th Annual Meeting of the Japanese College of Surgeons held in Tokyo. Each discussant is indeed an expert in postgraduate surgical training in different speciality and in different area of the globe. The president of this meeting, Prof. Noboru Yamate, planned to have an international symposium, in which a straight discussion was expected as to which direction we Japanese surgeons should steer our own ship of the training system to refine. We both believed that a consensus must 
be reached to establish a postoperative training system comparable in its essence to that of the United States, which many believe the most prominent as well as effective system today in the world. That is why we asked the discussants to note how they appreciate the American residency programs. American discussants fully appreciated their way, as had been expected. It is noteworthy that Dr. Machi, an active member of the surgical faculty of University of Hawaii, said there is no big change required in the essence of their programs, simply because their system had been well established. Dr. Stein, an internist having taught residents in Japanese hospitals for many years, gave us a detailed note of how to teach in residency training. It surely made us think of how poor we had been in these days since our government's abolishing the Internship more than 30 years earlier simply because of its inability to improve the Internship. Readers may be interested in the opinion directed thankfully straight to us by Dr. Novák, a skillful surgeon from Central Europe. Distinguished surgeons, Mr. Faulkner from Australia and Mr. Puri from Ireland, showed us an independent system well organized in each country. (Unfortunately we miss here the manuscript from Mr. Puri.) Two Japanese colleagues, Drs. Ito and Nishio, discussed the issue based on their own experience of once working as a resident in the United States some time ago.

At least we need a nationally-standardized clinically-oriented system of surgical training. Even if we appreciate the American residency system, mimicking the American way just for its hard frame, like years of training or order of speciality to train, will not bring about any fruitful development of our own system, unless we pay much more attention to the "soft" or so to say "the operating system" of it. Competition and frequent checking function along with skillful teaching methods seem to be essential to keep the system active and self-controlling. We would be more than happy, if members of our college enjoy the following articles and learn a lot to contribute to the work of modeling our training system.

We feel that there is just little time allowed before we start modeling our postgraduate surgical training system. Let us extend our sincere appreciation to all the discussants, most coming from abroad long way to the Meeting, and remained cooperative thereafter kindly to prepare the manuscript according to our request. We owe the success of Meeting in Tokyo to them all. 